\title{
Editorial
}

\section{Psychological Test Adaptation and Development - A New Beginning}

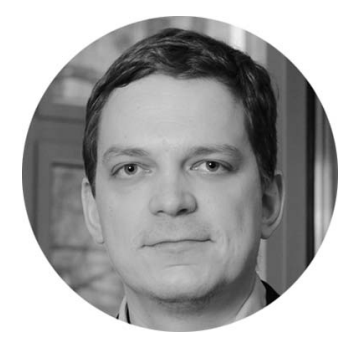

\author{
Matthias Ziegler \\ Department of Psychology, Humboldt-Universität zu Berlin, Germany
}

Abstract. Introductory editorial for the open access journal Psychological Test Adaptation and Development.

Keywords: assessment, open access, test adaptation, test development, test translation, EAPA, registered report

When I took over as editor for the European Journal of Psychological Assessment (EJPA) in 2013, one of the first editorial decisions I made was to change the journal's policy with regard to test translations. Basically, this meant that all papers which presented a translation without evidence for measurement invariance with the original measure or additional validity information were desk-rejected. Back then, I felt that this was a necessary step to further develop the journal and the "brand" EJPA. While it proved to be really good for the journal, I have to admit that I had not taken into consideration its impact on the field of assessment in Europe. The problem I had underestimated is that many projects in the area of assessment really do start with the translation or adaptation of an existing measure, and without a reputable journal prepared to publish the fruits of such work, researchers found it increasingly hard to publish internationally. Ever since, the echo I get from colleagues reflects this Janus-faced success. I was even told by some colleagues that working in the assessment area became less attractive as a result! This is something that did not go down easily with me, I must admit. Similar unease caused the European Association of Psychological Assessment (EAPA) to start looking for options to fill the gap that I had unintentionally created.

Fortunately, we found a publisher who was enthusiastic about our ideas, recognized the gap and needs that we had identified, and helped us toward a new beginning with the launch of Psychological Test Adaptation and Development (PTAD), whose founding editor I now have the honor to be. It is my pleasure to embark on this endeavor with an expert cast of associate editors: Tom Booth (University of Edinburgh, UK), Irena Burić (University of Zadar, Croatia), Miguel Angel Carrasco (Universidad Nacional de Educación a Distancia, Spain), Marjolein Fokkema (Leiden University, The Netherlands), Samuel Greiff (University of Luxembourg, Luxembourg), Nelson Hauck-Filho
(Universidade São Francisco, Brazil), Kai T. Horstmann (Humboldt University Berlin, Germany), Lena Lämmle (Medical School Hamburg, Germany), René Proyer (MartinLuther-University Halle-Wittenberg, Germany), John Rauthmann (Universität zu Lübeck, Germany), Jennifer Tackett (Northwestern University, Evanston, IL, USA), Michele Vecchione (Sapienza Universita di Roma, Italy), and Xiangdong Yang (East China Normal University, China).

PTAD is the official open access journal of the European Association of Psychological Assessment. As such, it fully embraces the concepts of open science. One of the consequences of this is that we welcome and encourage submissions in the form of Registered Reports. In general, PTAD is meant to be the outlet for research papers that portray the process of a test adaptation, such as a translation. In addition, papers reporting on test developments (e.g., from a trait to a state measure) are also very welcome. It should be noted here that, in the initial years, there will be a generous APC waiver program for authors wishing to publish in the journal (further information about this can be found here https://us.hogrefe.com/fileadmin/user_upload/ global/journals/Hogrefe_Publishing/Psychological_ Test_Adaptation_and_Development/PTA_APC_waiver_ form_fillable.pdf). So a lack of funds for publication fees is no reason to shy away from a submission.

In addition to providing an outlet for translations and adaptions (and thereby healing a self-inflicted wound!), another primary aim of PTAD is to improve the quality of psychological assessment in general by providing test users with quick-to-understand papers showcasing the psychometric qualities of the score(s) obtained using the measures that are described. PTAD also aims to be an attractive journal for test authors. In order to achieve these two goals, we ask authors to stick to relatively strict and detailed guidelines for submissions - which I go into in a separate article (Ziegler, 2020). While some may think this is 
intervening in the creative writing process, it will also be of advantage for our authors. One advantage is that review times can be very short because each paper follows similar guidelines on structure and logic. In combination with the opportunity to submit a registered report, authors can thus obtain expert feedback within a short period of time feedback that will result in improved quality of the papers in the journal. The guidelines also serve the function of helping test authors' plan and conduct their studies, integrating as they do current quality standards such as the APA Standards (AERA, APA, \& NMCE, 2014) or EFPA guidelines (EFPA Board of Assessment, 2013). As is the case in the EJPA, PTAD enforces the "ABC of test construction" (Ziegler, 2014) that encapsulates the essence of these quality standards.

As I mentioned, a separate article entitled "Psychological Test Adaptation and Development - How Papers Are Structured and Why" (Ziegler, 2020) goes into much more detail and explains the structure and "template" that we have developed for papers in PTAD. Please do read it!

All that remains for me to say now is that I am looking forward immensely to the start of the new journal - and to reading YOUR paper!

\section{References}

AERA, APA, \& NMCE. (2014). Standards for educational \& psychological testing. Washington, DC: AERA Publications.

EFPA Board of Assessment. (2013). EFPA review model for the description and evaluation of psychological and educational tests. Retrieved from http://www.efpa.eu/professional-development/ assessment

Ziegler, M. (2014). Stop and state your intentions! Let's not forget the ABC of test construction. European Journal of Psychological Assessment, 30, 239-242. https://doi.org/10.1027/1015-5759/ a000228

Ziegler, M. (2020). Psychological test adaptation and development - How papers are structured and why. Advance online publication. Psychological Test Adaptation and Development. https://doi.org/10.1027/2698-1866/a000002

Published online June 25, 2020

\section{Matthias Ziegler}

Department of Psychology

Humboldt University Berlin

Rudower Chaussee 18

12489 Berlin

Germany

zieglema@hu-berlin.de 